\title{
Role of diagnostic hysteroscopy in abnormal uterine bleeding and its histopathological correlation
}

\author{
Prashant Bhingare, Sanjaykumar Pagare, Shrinivas Gadappa, Rahul Ashok Ingle \\ Corresponding author: Dr. Rahul Ashok Ingle, Assistant Professor, Department of OBGY, Govt. \\ Medical College \& Hospital, Aurangabad, India; Email : rahulingle87@yahoo.in \\ Distributed under Attribution-Non Commercial - Share Alike 4.0 International (CC BY-NC-SA 4.0)
}

\begin{abstract}
Objectives: This study has been taken up to analyze the role of hysteroscopy in the evaluation of abnormal uterine bleeding (AUB) in terms of accuracy of hysteroscopic findings and contribution of the procedure to clinical diagnosis Methods: Prospective observational study at a tertiary care hospital in women undergoing dilatation \& curettage for gynaecological complaints. Results: 50 Patients who presented with AUB underwent panoramic hysteroscopy and subsequent dilatation and curettage (D \& C). Most common age group was 40-49yrs (52\%). Most of the patients (56\%) had symptoms for 6 months to 1 year and most common presenting symptom was menorrhagia (82\%) and polymenorrhea (10\%). Hysteroscopy reported 30 patients $(60 \%)$ as negative view and 20 patients $(40 \%)$ as abnormal view. The sensitivity, specificity, PPV and NPV for hysteroscopy was $95.23 \%, 100 \%, 100 \%$ and $96.66 \%$ respectively and for D\&C was $61.9 \%, 100 \%, 100 \%$ and $78.37 \%$ respectively. In the present study, in $82 \%$ patients; the results of hysteroscopy and curettage were in agreement. Conclusion: Hysteroscopy is a safe, reliable and quick procedure in the diagnosis of cases with abnormal uterine bleeding with high sensitivity, specificity and negative predictive value.
\end{abstract}

Keywords: Hysteroscopy, dilatation and curettage, menorrhagia.

Abnormal uterine bleeding is defined as any type of uterine bleeding in which the duration, frequency or amount is excessive for an individual patients. Almost one third of gynecological consultation and two-thirds of hysterectomies are due to abnormal uterine bleeding (AUB) ${ }^{1}$. The prevalence of abnormal uterine bleeding (AUB) is estimated to be $11-13 \%$ in the general population \& affects $10-30 \%$ of women from reproductive age group and up to $50 \%$ of perimenopausal age groupwomen. ${ }^{2}$ Incidence of AUB varies according to age and reproductive status of the women. Incidence increases as age of woman increased, reaching $24 \%$ in those aged $36-40$ years. ${ }^{3}$ The uterine bleeding has a wide range of diagnostic possibilities and confusion is generated when review and reports fail to outline the diagnostic evaluation of the patient who presents with abnormal uterine bleeding. In women with AUB, with normal to 12 weeks size uterus, the cause often remains obscure ${ }^{3}$. Goals of clinical management are primarily dependent upon attaining a correct etiological diagnosis. The history, physical and pelvic examination attempt to determine the site of the bleeding and its source. Traditionally ultrasonography and dilatation and curettage (D \& C) are most common investigations employed in the evaluation of AUB. Endometrial sampling is considered essential in AUB to confirm the benign nature of the disease and excluding malignancy by histopathological examination.

Received: $18^{\text {th }}$ June 2020. Peer review completed: $29^{\text {th }}$ July 2020, Accepted: $7^{\text {th }}$ August 2020.

Bhingare P, Pagare S, Gadappa S, Ingle RA. Role of diagnostic hysteroscopy in abnormal uterine bleeding and its histopathological correlation. The New Indian Journal of OBGYN. 2021; 7(2): 233-36. 
The New Indian Journal of OBGYN. 2021 (January-June);7(2)

This is important to decide the treatment modality.

Hysteroscopy has ushered a new era in the evaluation of abnormal uterine bleeding. Use of hysteroscopy in abnormal uterine bleeding is almost replacing blind curettage as it " visualize" and "confirm" the cause. A proper use of hysteroscopy to manage AUB adds a new dimension in handling this often perplexing problem. This study has been taken up to analyze the role of hysteroscopy in the evaluation of abnormal uterine bleeding in terms of accuracy of hysteroscopic findings, contribution of the procedure to clinical diagnosis and to correlate hysteroscopic findings with histopathological results.

\section{Materials and methods}

A prospective observational study was conducted after institutional ethical committee clearance in a tertiary care centre from September 2016 - September 2018, among 50 patients of reproductive, perimenopausal and postmenopausal age group, who were fitting into the inclusion criteria and who gave their consent for participation. A written valid informed consent was taken at the start of the study. The purpose of the study was duly explained and confidentiality of the information thereby obtained was maintained

Inclusion criteria: Patient of reproductive, perimenopausal and post menopausal age group who are admitted with history of abnormal uterine bleeding.

Exclusion criteria:

1) Patients with any demonstrable pelvic pathology like sizeable fibroids,

2) Cancer of cervix, cancer of vagina, cancer of endometrium,

3) Acute pelvic infections,

4) Pregnancy,

5) Unmarried,

6) Puberty menorrhagia

7) Coagulation disorder,

8) Patient on hormonal drugs like tamoxifen,

9) Patient with active profuse uterine bleeding were excluded from the study.

After applying inclusion and exclusion criteria, participants were evaluated with a proforma designed for the study was used. The routine investigations performed were blood routine, urine routine, blood grouping and $\mathrm{Rh}$ typing, BT, CT, HBsAg and pelvic ultra sonography. Other investigations (wherever necessary) LFT, KFT, RBS, ECG. All the patients in the study underwent diagnostic hysteroscopy followed by dilatation and curettage and curetting's were send for histopathological analysis.

Statistical analysis was done by using SPSS (version 19) for windows and data was presented as percentages. $\mathrm{P}$ value of $<0.05$ was considered significant. $\mathrm{P}$ value calculated using $\mathrm{F}$ test .

\section{Results and observations}

In present study, panoramic hysteroscopy was performed using $4 \mathrm{~mm}$ hysteroscope with 30 degree fore oblique lens in 50 patients who presented with abnormal uterine bleeding followed by dilatation and curettage. The curetted endometrium was send for histopathological analysis.

Table 1: Distribution of patients according to age ( $N=50)$

\begin{tabular}{lll}
\hline Age group & No. of patients & Percentage \\
\hline $20-29$ & 03 & 06 \\
$30-39$ & 17 & 34 \\
$40-49$ & 26 & 52 \\
$50-60$ & 4 & 08 \\
\hline
\end{tabular}

In present study, maximum age incidence was between $40-49$ yrs, 26 cases (52\%) (table 1). Majority of patients $41(82 \%)$ presented with menorrhagia (table 2 ).

Table 2: Distribution of patients according to clinical presentation and age $(\mathrm{N}=\mathbf{5 0})$

\begin{tabular}{|c|c|c|c|c|c|}
\hline $\begin{array}{ll}\text { Conditions } & \text { Age group }\end{array}$ & $\begin{array}{l}\text { 20-29 } \\
\text { yrs }\end{array}$ & $\begin{array}{l}\text { 30 }-39 \\
\text { yrs }\end{array}$ & $\begin{array}{l}40-49 \\
\text { yrs }\end{array}$ & $\begin{array}{l}50-60 \\
\text { yrs }\end{array}$ & Total \\
\hline Menorrhagia & 2 & 15 & 23 & 1 & 41 \\
\hline Polymenorrhea & 1 & 2 & 2 & 0 & 5 \\
\hline Post-menopausal bleeding & 0 & 0 & 1 & 3 & 4 \\
\hline Total & 3 & 17 & 26 & 4 & 50 \\
\hline
\end{tabular}

Among the 50 patients majority: 28 patients (56\%) had symptoms for 6 months to 1 years, 15 patients (30\%) had symptom for less than 6 months and 7 patients $(14 \%)$ had symptom for more than 1 years (table 3 ).

Table 3: Distribution of patients according to duration of symptoms $(\mathrm{N}=50)$

\begin{tabular}{lll}
\hline Duration of symptoms & No. of patients (N=50) & Percentage \\
\hline$<6$ months & 15 & $30 \%$ \\
6 Months - 1 year & 28 & $56 \%$ \\
$>1$ year & 7 & $14 \%$
\end{tabular}

$>1$ year $\quad 7 \quad 14 \%$

Abnormal findings were seen in 20 patient (40\%) while in remaining 30 patients $(60 \%)$ no abnormality was detected (negative hysteroscopic view) (table 4).

Table 4: Distribution of patients according to findings at hysteroscopy

\begin{tabular}{lll}
\hline Hysteroscopic findings & No. of patients $(\mathbf{N}=\mathbf{5 0})$ & Percentage \\
\hline Normal endometrium & 30 & $60 \%$ \\
Endometrial hyperplasia & 7 & $14 \%$ \\
Endometrial polyps & 9 & $18 \%$ \\
Submucous myoma & 3 & $6 \%$ \\
Endometrial atrophy & 1 & $2 \%$
\end{tabular}

Of 37 normal cases (74\%) reported on histopathology 13 cases had abnormal findings, most common was endometrial hyperplasia in 8 cases (16\%) (table 5).

In all patients vomiting subside by its own. No medication was required. Also bleeding per vaginum, subside by its own. No medication was required. 
The New Indian Journal of OBGYN. 2021 (January-June);7(2)

Table 5: Distribution of patients according to findings at endometrial histopathology $(\mathrm{N}=\mathbf{5 0})$

\begin{tabular}{lll}
\hline Histopathology findings & No. of patients (N=50) & Percentage \\
\hline Normal & 37 & $74 \%$ \\
Endometrial hyperplasia & 8 & $16 \%$ \\
1. Cystic & 5 & \\
$2 . \quad$ Simple & 1 & \\
$3 . \quad$ Atypical & 1 & \\
4. Adenomatous & 1 & $6 \%$ \\
Endometrial polyps & 3 & $2 \%$ \\
Submucous myoma & 1 & $2 \%$ \\
Atrophic endometrium & 1 & \\
\hline
\end{tabular}

Both hysteroscopy and curettage were accurate when an abnormality was diagnosed, giving a specificity 100 and positive predictive value (PPV) of 100 (for both) (table 7).

\begin{tabular}{lll} 
Table 6: Complications & among patients noted postoperatively \\
\hline Complications & No. of cases $(\mathbf{N}=\mathbf{5 0})$ & Percentage \\
\hline Vomiting & 10 & $20 \%$ \\
Bleeding PV & 1 & $2 \%$ \\
\hline
\end{tabular}

\begin{tabular}{lll}
\multicolumn{3}{l}{ Table 7: Comparison of Validities } \\
\hline Categories & Hysteroscopy in \% & Dilatation and curettage in \% \\
\hline Sensitivity & 95.23 & 61.9 \\
Specificity & 100 & 100 \\
PPV & 100 & 100 \\
NPV & 96.66 & 78.37 \\
Accuracy & 98 & 84 \\
\hline
\end{tabular}

\section{Discussion}

Abnormal uterine bleeding is one of the most frequently encounter condition among patients visiting gynecology OPD. The youngest patient in this study was 24 yrs old and oldest was 60 yrs. Maximum age incidence was between 40 - 49 yrs, 26 cases $(52 \%)$. Swati Singh et al ${ }^{4}$ found that maximum age incidence was between $31-40$ years in range between 22 - 70 years. V Radha Lakshmi et al ${ }^{5}$ reported maximum age incidence between $46-50$ years. In Gazal Garg et al ${ }^{6}$ series among 60 patient commonest age incidence was between $46-55$ years. Parul Sinha et al ${ }^{7}$ reported that mean age of patients was $36.4 \pm 7.6$ years.

As shown in table number 2, majority of patients $41(82 \%)$ presented with menorrhagia. Second commonest group had polymenorrhea 5 patients $(10 \%)$. There were 4 cases $(8 \%)$ with postmenopausal bleeding. Swati Singh et al ${ }^{4}$ series had $32 \%$ cases of menorrhagia followed by polymenorrhagia and oligomenorrhoea; in V Radha Lakshmi et al ${ }^{5}$ series menorrhagia was the most common bleeding pattern observed in $55 \%$, followed by polymenorrhagia in $13 \%$ of cases; in Gazal Garg et al ${ }^{6}$ series menorrhagia was seen in $43 \%$ of cases followed by polymenorrhagia. Parul Sinha et al ${ }^{7}$ reported that $66.1 \%$ cases of menorrhagia, $30.4 \%$ polymenorrhoea and $3.6 \%$ intermenstrual bleeding.

Of the 20 cases with abnormal findings on hysteroscopy, commonest seen was endometrial polyp ( 9 cases, $18 \%$ ) followed by endometrial hyperplasia ( 7 cases, $16 \%$ ), followed by and submucous myoma ( 3 cases, $6 \%$ ) and one case $(2 \%)$ of endometrial atrophy. Swati Singh et al ${ }^{4}$ found endometrial hyperplasia in $26 \%$, endometrial polyp in $8 \%$ and submucous myoma in $7 \%$ of cases. V Radha Lakshmi et al ${ }^{5}$ found endometrial hyperplasia in $20 \%$, endometrial polyp in $13 \%$ and submucosal myoma in $11 \%$ of cases; Gazal Garg et al ${ }^{6}$ found that endometrial polyps were most common cause of AUB, comprising $26.67 \%$ of total cases, followed by submucous myoma attributing to $23.33 \%$ of cases, fuctional endometrium with normal appearance was seen in $18.33 \%$ of the cases, followed by endometrial hyperplasia in $11.66 \%$; Parul Sinha et al ${ }^{7}$ found endometrial polyp in $16.1 \%$ and submucous myoma in $10 \%$ of cases.

As shown in table 7 , the ability to diagnose a lesion (sensitivity) was more with hysteroscopy in comparison to dilatation and curettage (95.23 v/s 61.9), while a negative diagnosis was less wrongly made with hysteroscopy (NPV $96.66 \mathrm{v} / \mathrm{s}$ 78.37). In present study hysteroscopy missed the diagnosis of 1 case of endometrial hyperplasia. The accuracy of hysteroscopy in this study was $98 \%$ and that of endometrial histopathology was $84 \%$.

\section{Conclusion}

Hysteroscopy is a safe, reliable and quick procedure in the diagnosis of cases with abnormal uterine bleeding with high sensitivity, specificity and negative predictive value. This study confirms that hysteroscopy is superior to curettage in evaluating patients with abnormal uterine bleeding.

\section{Conflict of interest: None. Disclaimer: Nil.}

\section{References}

1. Van Dongen H, de Kroon C, Jacobi C, TRimbos B, Jansen F. Diagnostic hysteroscopy in abnormal uterine bleeding: a systematic review and meta-analysis. BJOG 2007; 114: 664-75.

2. Hatasaka H. The evaluation of Abnormal Uterine Bleeding. Clinical Obstet Gynaecol. 2005; 48(2): 258-73.

3. Erik Qvigstad I. Current treatment options for abnormal uterine bleeding:an evidence - based approach. Best Practice \& Research Clinical Obstetrics and Gynecology. 2007; 21(6): 905-13.

4. Singh S, Taneja BK, Singh P, Ahlawat R. Int J Reprod Contracept Obstet Gynecol. 2014; 3(3): 544-51. 
The New Indian Journal of OBGYN. 2021 (January-June);7(2)

5. Radha Laxmi V, Sunitha C, Sofia Sowjanya M. Role of Diagnostic Hysteroscopy in Abnormal Uterine Bleeding and its Histopaathological correlation. Indian Journal of Applied Reserch. 2015; 5(3): 2249-555X .

6. Garg G, Agrawal K, Sanghi S. A study of the Role of Hysteroscopy in Abnormal Uterine Bleeding. Journal of Gynecologic surgery. 2017; 33(6): 226-30.

7. Sinha P, Yadav N, Gupta U. Use of Hysteroscopy in Abnormal Uterine Bleeding: An Edge Over Histopathological Examination. J Obstet Gynaecol India. $2018 \mathrm{Feb}$; 68(1): 45-50.
Prashant Bhingare ${ }^{1}$, Sanjaykumar Pagare ${ }^{2}$, Shrinivas Gadappa $^{3}$, Rahul Ashok Ingle ${ }^{4}$

${ }^{1}$ Associate Professor, Department of OBGY, Govt. Medical College \& Hospital, Aurangabad, India;

${ }^{2}$ Assistant Professor, Department of OBGY, Govt. Medical College \& Hospital, Aurangabad, India;

${ }^{3}$ Professor and Head, Department of OBGY, Govt. Medical College \& Hospital, Aurangabad, India;

${ }^{4}$ Assistant Professor, Department of OBGY, Govt. Medical College \& Hospital, Aurangabad, India. 